business and personal given the opportunity to respond optimally to environmental constraints.

\title{
0941 BURN OUT AND CRAFT EMERGENCY
}

P Marien*, L Auvert, J Porras, G Michel Correspondence: Universit Victor Segalen Bordeaux 2, U.F.R. Sciences de I'Homme - Bt.H - Porte HD 1 Laboratoire de Psychologie "Sant \& Qualit de Vie" EA 41393 ter, Place de la Victoire 33076 Bordeaux, French Southern Territories

\subsection{6/ip.2010.029215.941}

Burnout $(\mathrm{BO})$ is an international phenomenon studied. It is very important in the sectors of Health, Education and Defence but remains largely unexplored among firefighters, policemen (Parent-Thirion et al, 2005; Lavillunires et al. 2007; Lourel et al., 2008). Most studies have tried to apprehend the $\mathrm{BO}$ or through individual characteristics or through the environmental requirements but neglecting the relationship that both could maintain.

Objective To investigate predictors of $\mathrm{BO}$ among French fire fighters, policeman and emergency workers.

Method 100 fire fighters, 100 emergency workers will answer to the Temperamental and Character Inventory (TCI-56; Rigozzi and Rossier, 2005), to Job Stress Survey adapted to urgency workers (JSS-F, Marien, Auvert and Michel, 2009), to Coping Stress Inventory (CISS; Rolland et al., 1994); to the Maslach Burnout Inventory (MBI; Dion and Teissier, 1994).

Preliminary Results $\mathrm{BO}$ is caused by the interaction between occupational stress and coping. In this case, personality moderate this relationship.

Discussion These findings emphasise the importance of differentiating these individuals according to their job requirements vary by rank and focus on the importance of subjective dimension in this syndrome. They bring to light the importance of interactional process between individuals characteristics and environmental constraints. This can orient some intervention approaches that can be access on the motivational aspect. In this case, the job could be for a redefinition of goals but also on expanding the flexibility and skills to both 